\title{
Journal of the Mechanics and Physics of Solids
}

\section{Corrigendum}

\section{Corrigendum to "Micromechanics of pyramidal indentation in fcc metals: Single crystal plasticity finite element analysis" [J. Mech. Phys. Solids 2008, 56, 3277-3303]}

\section{J. Alcalá ${ }^{\mathrm{a}, \mathrm{c}, *}$, O. Casals ${ }^{\mathrm{a}, \mathrm{d}}$, J. Očenášek ${ }^{\mathrm{a}, \mathrm{b}}$}

a GRICCA, EUETIB, Universitat Politècnica de Catalunya, Barcelona 08028, Spain

${ }^{\mathrm{b}}$ Christian Doppler Laboratory of Material Mechanics of High Performance Alloys, Technische Universität München, D-85748 Garching, Germany

${ }^{\mathrm{c}}$ Faculty of Aerospace Engineering, Technion-Israel Institute of Technology, Haifa 32000, Israel

d Centre des Matériaux/UMR 7633, Ecole des Mines de Paris/CNRS, BP 87, F-91003 Evry, France

\section{A R T I C L E I N F O}

\section{Article history:}

Received 2 February 2010

Accepted 9 February 2010

The authors have found the following errors in their manuscript which could not be corrected prior to publication. In Eq. (17), $h_{\mathrm{s}}$ shall be replaced by $h_{\mathrm{I}}$ and $\tau_{\mathrm{I}}$ by $\tau_{\mathrm{s}}$. Also, by virtue of Eqs. (A.8) and (A.11) for $a_{\alpha \alpha}$, the following relation holds for $h_{\mathrm{I}}$ in the modified BW model instead of the constant value of $0.12 \mathrm{MPa}$ reported in Table 3:

$$
h_{\mathrm{I}}=\frac{\mu}{2 K}\left[\kappa_{\alpha \alpha} \ln \left(b \sqrt{\rho^{(\alpha)}}\right)\right]^{2} .
$$

where $\mu \kappa_{\alpha \alpha}^{2} / 2 K \approx 0.12$.

* Corresponding author at: GRICCA, EUETIB, Universitat Politècnica de Catalunya, Barcelona 08028 , Spain. Tel.: +34 934016287 ; +34 93 4016706.

E-mail address: jorge.alcala@upc.es (J. Alcalá). 